\title{
Occurrence and Fate of Amoxicillin and Penicillin G Antibiotics in Hospital Wastewater Treatment Plants: A Case Study - Gonbad Kavous, Iran
}

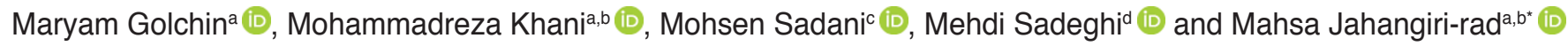 \\ ${ }^{a}$ Department of Environmental Health Engineering, Faculty of Health and Medical Engineering, Tehran Medical Sciences, Islamic Azad University, Tehran, Iran \\ ${ }^{b}$ Water Purification Research Center, Tehran Medical Sciences, Islamic Azad University, Tehran, Iran \\ 'Environmental and Occupational Hazards Control Research Center, Shahid Beheshti University of Medical Sciences, Tehran, Iran \\ ${ }^{d}$ Environmental Health Research Center, Faculty of Health, Golestan University of Medical Sciences, Gorgan, Iran
}

Received 08 February 2020, revised 17 October 2020, accepted 27 October 2020

\begin{abstract}
Release of antibiotics to the environment as a result of wastewater effluent discharge is a cause for concern worldwide, as they pose a potential threat to human health and the earth ecosystem. Penicillin and amoxicillin are widely used antibiotics. Despite their rapid hydrolysis in aqueous matrices, their presence in the environment is widely investigated. The current study reported and analysed the current state of four hospital wastewater treatment plants (WWTPs) in Gonbad Kavous, Iran, during 2019, from the perspective of amoxicillin and penicillin G removals. WWTPs were sampled at various stages of the treatment process to determine at which stage the antibiotics are being removed. Concentrations of amoxicillin and penicillin $\mathrm{G}$ in raw wastewater, analysed by HPLC, varied from 0.35 to 1.02 and $0.02-0.31 \mu \mathrm{gL}^{-1}$, respectively. These values reduced in the final effluent, corresponding to overall efficiency in removing the studied antibiotics of $20-60.5 \%$. Anaerobic processes (i.e. septic tank) slightly outperformed aerobic biological processes for both antibiotics' removal, and penicillin $\mathrm{G}$ was removed more efficiently than amoxicillin. Effects of wastewater physicochemical properties, including chemical oxygen demand (COD), biochemical oxygen demand (BOD), and total suspended solids (TSS) on antibiotics removal, were also studied. Whereas statistically significant correlations were noticed between COD, amoxicillin and penicillin G removals, their decline showed no correlation with TSS removal. Our study shows that despite the deployment of treatment plants, a considerable amount of antibiotics is released into receiving water bodies, resulting in significant amounts of these pharmaceuticals entering the environment. There is abundant room for further progress in the detection and quantification of pharmaceuticals and other emerging contaminants in hospital wastewaters and their metabolites and biodegradation products.
\end{abstract}

KEYWORDS

amoxicillin; penicillin G; high-performance liquid chromatography; hospital wastewater treatment plants; removal

\section{Introduction}

In recent years special attention has been paid to the existence of refractory emerging contaminants (RECs) in wastewaters, groundwater and surface waters. Emerging contaminants refer to unregulated pollutants which are scrutinised for future regulation. These chemicals are persistent in the environment and have detrimental effects on the aquatic ecosystem. ${ }^{1}$ Hospital wastewater (HWW) is known to be hazardous to both humans and the environment due to the presence of pharmaceutical compounds, pathogens and other chemicals, among others. ${ }^{2}$ Antibiotics, analgesics, $\beta$-blockers and other chemical substances, including disinfectants, are the main emerging pollutants found in $\mathrm{HWW}^{3}$ The main focus of researches, however, is on pharmaceuticals (particularly antibiotics) due to the worldwide use and their potential health effects like endocrine disruption and sexual disturbance. ${ }^{4}$ Antibiotics detected in hospital wastewaters could be classified into three main groups: quinolones, sulphonamides, and macrolides..$^{5-7}$ Statistically, global consumption of antibiotics has increased up to $>30 \% .{ }^{8,9}$ Previous studies have shown that the rate of antibiotics consumption in Iran is three times more than their global average. ${ }^{10,11}$ Based on different studies, amoxicillin (AMX), ampicillin, metronidazole, erythromycin, and tetracycline are the most common antibiotics used in Iran's hospitals. ${ }^{12,13}$ The serum penicillin G (PEN G) and AMX have

*To whom correspondence should be addressed

Email: m.jahangiri@iautmu.ac.ir or mahsajahangiri_64@yahoo.com half-lives of 4.1 days and 61.3 minutes, respectively. ${ }^{14}$

A high proportion of prescribed antibiotics are excreted in the urine (55-80\%) and faeces (4-30\%) in the form of un-metabolised substances, metabolites, or conjugated with inactivating substances. ${ }^{4}$ In recent years, a decrease in the number of antibiotics efficacious in treating human and livestock infectious diseases has been observed due to the development of antibiotic resistance. This resistance has resulted in what the World Health Organization (WHO) describes as a global threat to human health. ${ }^{9}$ The presence of antibiotic residues coupled with the high bacterial density, nutrient and oxygen conditions in the biological treatment systems of wastewater treatment plants may advance exemplary conditions for the transfer of antibiotic resistance genes, resulting in the dispersion of antibioticresistant bacteria into the environment. ${ }^{6}$ Given that the nature of antibiotics is to kill or inhibit the growth of microorganisms, the activity of most microbial communities in WWTPs have ceased or developed resistant mechanisms as a consequence of the release of antibiotics into waste treatment units. ${ }^{7}$ The obstacles in removing emerging pollutants (also known as micropollutants) from wastewater is their micro-concentrations $\left(10^{-3}-10^{-6} \mathrm{mgL}^{-1}\right)$, which is considerably smaller than macro pollutants, such as 5-day BOD $\left(\mathrm{BOD}_{5}\right), \mathrm{COD}$ and nitrogen, among others, which the conventional WWTPs plants are designed for and operation is based on. ${ }^{6}$ In addition, the varying properties of these substances, such as solubility, volatility, molecular weight and polarity, affect their removal in WWTP. ${ }^{15}$

At present, several physicochemical and biological methods, such as conventional activated sludge (CAS) ${ }^{16}$ membrane bio- 
reactor (MBR) ${ }_{1}^{17}$ constructed wetlands and stabilisation ponds ${ }^{18}$, and septic tanks have been applied to remove pharmaceuticals from wastewater. ${ }^{19}$ Until now, little research has focused on the incidence and destiny of antibiotics during hospital wastewater treatment in Iran. Hence, it seems indispensable to apprehend the amount of the most commonly used antibiotics (AMX and PEN G) in raw and treated hospital wastewater. Furthermore, physiochemical parameters including $\mathrm{BOD}_{5}, \mathrm{COD}$ and TSS were also analysed in the influent and effluent to determine their possible effects on antibiotics removal.

\section{Experimental}

2.1. Sampling sites and wastewater treatment plants properties

Gonbad Kavous is located in Golestan Province, northeast of Iran, near the Caspian sea, with an approximate area of 2059 ha and an estimated population of 151910 in 2017. The county consists of two districts and has two cities: Incheh Borun and Gonbad-e Qabus (Fig. 1).

Samples were taken at different stages of the treatment process in four selected hospitals. Three hospitals are general teaching hospitals under the auspices of Gorgan University of Medical Sciences, and one is private. The university hospitals are medium-sized, with $96-140$ beds. The private hospital is

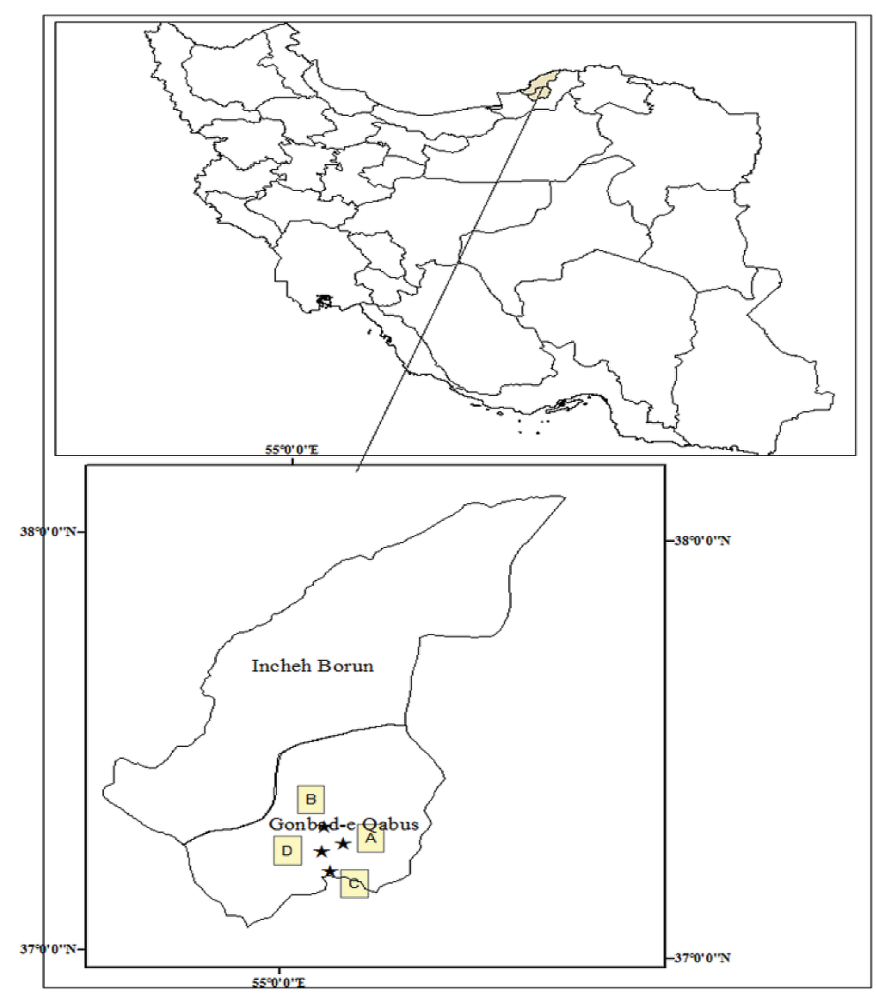

Figure 1 Sampling locations of hospital wastewater treatment plants in Gonbad-Kavous

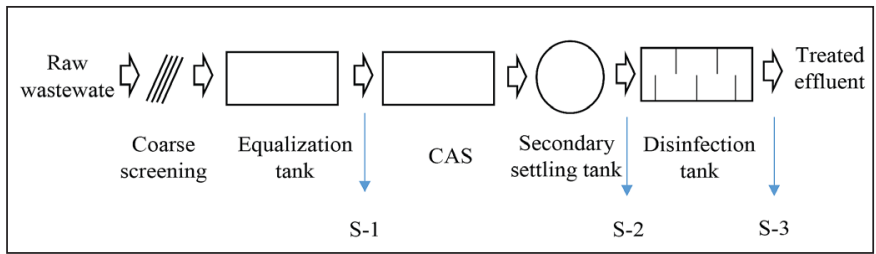

Figure 2 Sampling points from the influent and effluent of hospital wastewater treatment plants

also small-sized with 50 beds. Three stages of the treatment process were considered for sampling: Influent following coarse screening and equalisation tank (S1), secondary biological treatment effluent (S2), and the final effluent after disinfection process (S3) (Fig. 2). Samples were collected during autumn 2019 (twice each month; $\mathrm{n}=76$ ). In the university/ governmental hospitals (A, B and C), conventional activated sludge (CAS) processes are applied with respective treatment capacities of $1.7,1.7$, and $2 \mathrm{~m}^{3} \mathrm{~h}^{-1}$. However, a septic tank with a treatment capacity of $1.5 \mathrm{~m}^{3} \mathrm{~h}^{-1}$ is used to treat wastewater in the private hospital (D). In all hospitals, treated effluents are finally discharged into rivers through collective run-off systems.

\subsection{Sample analysis}

Glass bottles (1 L) attached to steel wire were used to collect samples from turbulent wastewater stream by an on-site technician. The sample was then passed through a $0.45 \mu$ glass fibre filter to eliminate suspended solids. The filtered samples were subsequently subjected to $\mathrm{pH}$ adjustment $(\mathrm{pH}=4)$ by adding formic acid and were kept in a refrigerator until analysis.

All chemicals used in the current study were of analytical reagent grade. AMX, PEN G, buffer phosphate and acetonitrile were purchased from Merk Co. Antibiotics were dissolved in a buffer phosphate/acetonitrile $(70 / 30 \mathrm{v} / \mathrm{v})$ solution. All solvents were of HPLC grade. Properties of selected antibiotics are presented in Table 1.

The concentrations of selected antibiotics were determined using a Knauer HPLC (C18 ODS column; $250 \mathrm{~mm} \times 4.6 \mathrm{~mm}$ $\times 5 \mathrm{~mm}$ ) with a UV detector at a wavelength of $158 \mathrm{~nm}$ for AMX and $220 \mathrm{~nm}$ for PEN G with $20 \mu \mathrm{L}$ injection volumes. The mobile phase also included buffer phosphate with $\mathrm{pH}=4.5$ and acetonitrile (a volumetric ratio of 70:30) and 40:60 volumetric ratio of methanol/water for both antibiotics. The injection flow rate was fixed at $1 \mathrm{~mL} \mathrm{~min}{ }^{-1}$. Each stage of the experiment was repeated twice, and the mean is reported here.

The HPLC results obtained from 5 standard concentrations of AMX and PEN G showed a wide linear dynamic range with the equations: $Y=159199 x-25508 y$ (in which, $Y$ is peak area and $\mathrm{x}$ is the concentration of the AMX, $\left.R^{2}=0.9995\right)$ and $\mathrm{Y}=148521 \mathrm{x}$ - 222901y (in case of PEN G, $R^{2}=0.985$ ); $n=10, S D= \pm 0.25$.

The chromatogram obtained from (a) PEN G and (b) AMX injections are shown in Figure 3; $\mathrm{n}=4$.

Table 1 Details of selected antibiotics in the current study

\begin{tabular}{|c|c|c|c|c|c|c|}
\hline Common name & $\begin{array}{l}\text { Chemical } \\
\text { formula }\end{array}$ & $\begin{array}{l}\text { Chemical } \\
\text { structure }\end{array}$ & CAS-number & $\begin{array}{c}\text { Mol. Mass } \\
\left(\mathrm{g} \mathrm{mol}^{-1}\right)\end{array}$ & $\log k_{o w}$ & $\begin{array}{c}\mathrm{S} \\
\left(\mathrm{gL}^{-1}\right)\end{array}$ \\
\hline Amoxicillin & $\mathrm{C}_{16} \mathrm{H}_{19} \mathrm{~N}_{3} \mathrm{O}_{5} \mathrm{~S}$ & & 26787-78-0 & 365.4 & 0.87 & 4 \\
\hline Penicillin G & $\mathrm{C}_{16} \mathrm{H}_{18} \mathrm{~N}_{2} \mathrm{O}_{4} \mathrm{~S}$ & & $61-33-6$ & 333.40 & 1.83 & 0.21 \\
\hline
\end{tabular}


Physicochemical parameters, including TSS, COD and 5-day BOD, were measured according to standard methods. ${ }^{20}$

\subsection{Data analysis}

Mass balance analyses were applied to assess how effective aerobics conditions of hospital WWTP removal of antibiotics from the wastewater flow is. Based on the following equation, the removal efficiencies were calculated assuming the influent and effluent of AMX and PEN G from the aerobic systems;

Removal efficiency $(\mathrm{RE})=$

$$
\left(C_{i} V \text { influent }\right)-\left(C_{e} V \text { effluent }\right) /\left(C_{i} V \text { influent }\right)
$$

where $C_{i}, C_{e}$ are mean concentrations of antibiotics in the influent and effluent $\left(\mu \mathrm{gL}^{-1}\right)$, respectively. $V$ denotes the quantity of wastewater $\left(\mathrm{L} \mathrm{day}^{-1}\right)$ entering hospital WWTPs. The Friedman test was conducted using SPSS 22 to test the impact of monthly variations for antibiotics removal. The Spearman correlation analysis was also used to evaluate the correlation between antibiotics removal and studied operational physiochemical parameters.

Since the on-site three-chamber septic tank with a volume of $75 \mathrm{~m}^{3}$ and an approximate retention time of 2 days is the only HWWT provided for the private hospital (D), the removal efficiency of the septic tank was calculated as

\section{Removal efficiency $(\mathrm{RE})=$}

[(Influent of antibiotics) $-($ Effluent of antibiotics $)] \times 100$

\section{Results and Discussion}

3.1. Concentration of selected antibiotics in influent and effluent of WWTPs

The concentrations of AMX and PEN G in influents (after equalisation tank) and following biological treatment of four hospitals are shown in Fig. 4 a and b, respectively. The respective mean concentrations of AMX and PEN G in the influent ranged from 13.3-18.47 $\mu \mathrm{gL}^{-1}$ and 3.12-4.75 $\mu \mathrm{gL}^{-1}$. They were observed in influent samples of the studied hospitals with the maximum concentrations of 25 and $6.6 \mu \mathrm{gL}^{-1}$, respectively.

In all the experiments, AMX presented approximately 4 folds higher concentrations compared to PEN G. Specifically, the higher concentration of AMX with 25 and $21.95 \mu \mathrm{gL}^{-1}$ were detected in influents of hospitals B and C, respectively. Appreciable values of antibiotics in raw wastewater corresponds with their elevated levels of consumption in these hospitals. ${ }^{21}$ The elevated levels of PEN G and AMX noticed in the current study may be associated with their delivery along with discharging of their residues into hospitals sewers. These $\beta$-lactam type antibiotics are the most commonly prescribed and widely used antibiotics to treat bacterial infections by Gram-negative and Gram-positive genera, like Streptococcus, Gonococcus and Staphylococcus. ${ }^{22}$ In comparison with Iran's case, PEN G and AMX are the most consumed antibiotics in other countries., ${ }^{1,23}$ However, minimum amounts of them were found in the urban wastewater treatment plant effluents. The $\beta$-lactam ring in PEN G and AMX structures are known to be transience, which
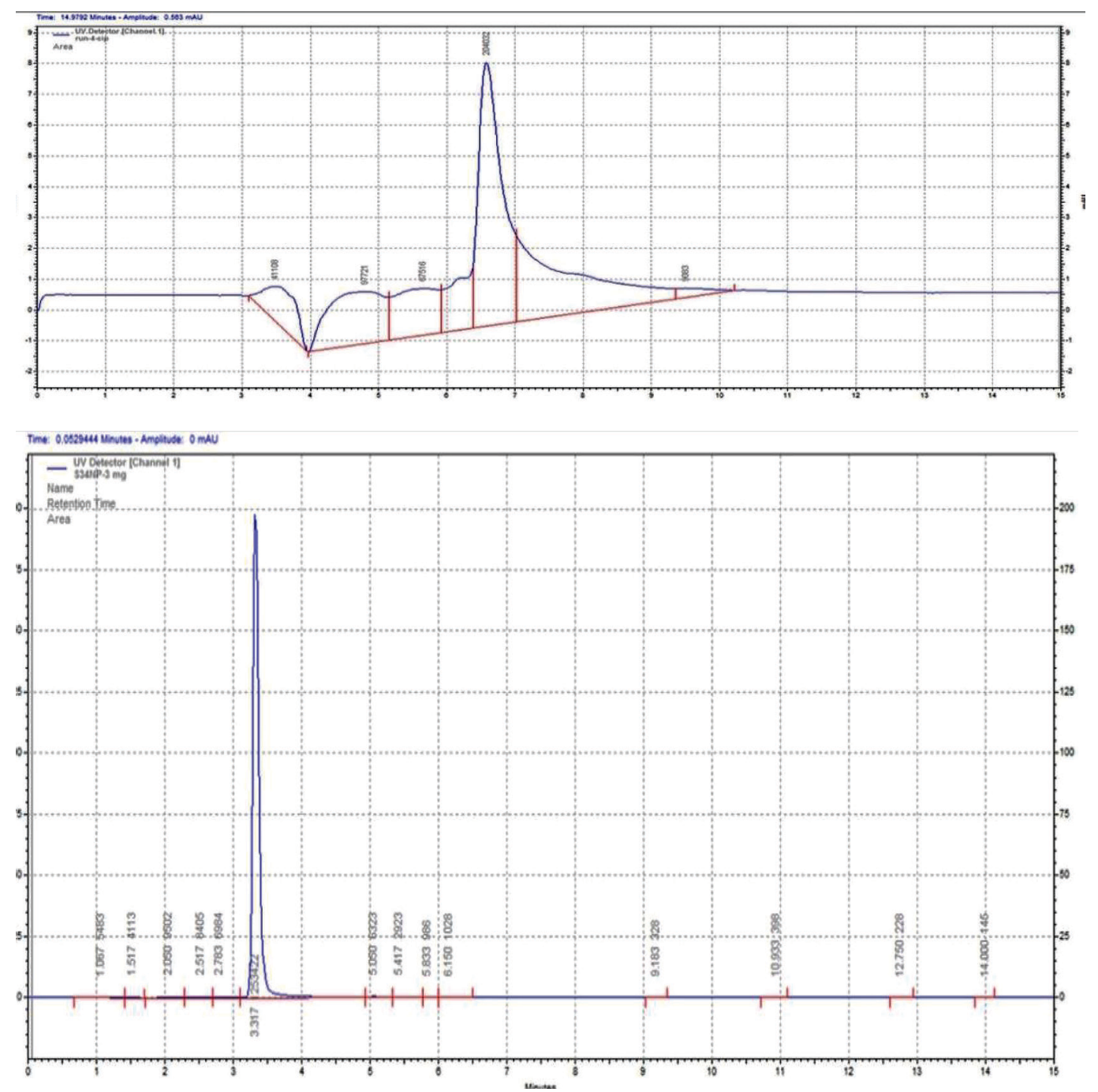

Figure 3 Chromatogram of spiked (a) AMX and (b) PEN G extracted at 158 and 220nm, respectively. 
(a)
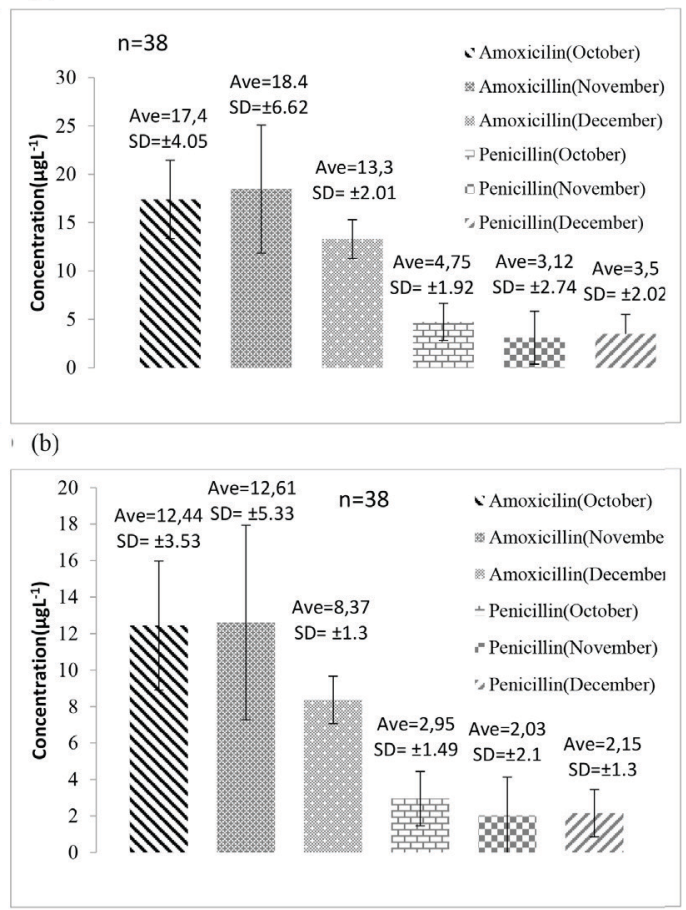

Figure 4 Variations in antibiotics detected levels in the (a) influent and (b) after biological processes of surveyed hospitals during autumn

leads to their further degradation by chemical hydrolysis and/ or $\beta$-lactamase-producing bacteria over time. ${ }^{24}$ AMX and PEN $G$ have also been detected in high concentrations of 0.36 and $0.13 \mu \mathrm{gL}^{-1}$ in raw samples of Tanzanian wastewater treatment plants. ${ }^{24}$ It is worth noting that many of the pharmaceuticals having clinical importance might not be present as their parent compounds in WWTP but have been detected as metabolite substances..$^{25}$

The highest mean residue concentrations in the effluent were 12.44, and $2.95 \mu \mathrm{gL}^{-1}$ for AMX and PEN G. Heidler and Halden ${ }^{26}$ reported fairly similar amounts of antibiotics in the effluent of wastewater, these values for antibiotics are much higher than formerly reported by some other researchers. ${ }^{27,28}$ Extensive studies have been conducted on the occurrence of antibiotics in raw and treated wastewater of WWTPs, including urban and hospitals. ${ }^{26,29-31}$ Our results imply that the concentrations of selected antibiotics in HWWTPs are higher than most reported values. These values could be mainly attributed to the fact that Iran's antibiotics consumption is three times higher than the global average. ${ }^{32}$ Moreover, the $\beta$-lactams are one of the most extensively used classes of antibiotics in Iran, which may cause the development of resistant bacteria. ${ }^{33}$ Kihampa $^{24}$ reported fairly high concentrations of AMX as compared to ampicillin and ciprofloxacin in the influents and effluents of monitored hospitals. Likewise, in a study conducted by Li et al. ${ }^{33} 389 \mathrm{mgL}^{-1}$ of penilloic acid, a degradation product of PEN G, was detected in hospital WWTP effluent with $153 \mu \mathrm{gL}^{-1}$ of the parent compound that remained intact. ${ }^{33}$ Several reasons are known for diverging values of antibiotics in the influent and effluent of hospital WWTPs; among them, the main contributors are the number of beds, the average water consumption, the number and types of wards, the season of taking samples, the management policies and the type of wastewater treatment processes use. ${ }^{34}$

\subsection{Antibiotics removal and loading estimations of WWTPs}

Table 2 shows the influent loading and removal of each antibiotic in the studied hospitals. The influent loading varied from 0.25 to $1.02 \mathrm{~g} \mathrm{~d}^{-1}$ and 0.02 to $0.3^{1} \mathrm{~g} \mathrm{~d}^{-1}$ for AMX and PEN G in the aerobic processes. Approximately the same influent loadings of AMX and PEN G were observed in septic tank operating in hospital D. Hospitals operated with conventional activated sludge showed almost similar loads. The highest influent mean load was observed for AMX in hospital A. Removal efficiency of each antibiotic was calculated by comparing its mass load in HWWTP influent and effluent.

The removal efficiencies altered from 16.9 to $38.3 \%$ and 22.6 to $46 \%$ for AMX and PEN G in the aerobic processes, respectively. However, higher removal rates were observed for both antibiotics in anaerobic conditions with the maximum removal of 52 and $57.9 \%$ of AMX and PEN G. Li et al. ${ }^{33}$ previously reported penicillin removal efficiency of $96.7 \%$ in WWTP, including successive treatment of anaerobic, hydrolysis and two aerobic units. The processes in the current study were insufficient to entirely remove both antibiotics as various concentrations were detected in effluents $\left(4.7-16.25 \mu \mathrm{g}^{\mathrm{L}-1}\right.$ for AMX and $0.35-4.4 \mu \mathrm{gL}^{-1}$ for PEN G).

Carballa and colleagues ${ }^{3} 5$ have reported a $20-50 \%$ removal efficiency for some antibiotics during the initial treatment. Even though the reported performance was increased up to $70 \%$ after the activated sludge process. During wastewater treatment processes, antibiotics undergo a battery of processes, including adsorption on suspended solids, degradation by microbial communities, or destruction through the disinfection processes that produce $\mathrm{C}_{\mathrm{O}} 2$ and water due to ultimate oxidation ${ }^{36}$ The removal and fate of antibiotics in remediation facilities are generally determined by various factors. These factors include physical and chemical characteristics (solubility, volatility, photo-degradation, biodegradability, etc.) of the pollutants and operational parameters (solid retention time (SRT), hydraulic retention time (HRT), $\mathrm{pH}$, temperature, etc.) of the treatment plants. ${ }^{37}$ The hydrophobicity of the organic compounds, i.e., the octanol-water partition coefficient $\left(\mathrm{K}_{\mathrm{ow}}\right)$, governs their solubility ${ }^{38}$ Compared with compounds having high values of $\log \mathrm{K}_{\mathrm{ow}}\left(\log \mathrm{K}_{\mathrm{ow}}>5\right)$, antibiotics with low molecular weights and $\log \mathrm{K}_{\mathrm{ow}}\left(\log \mathrm{K}_{\mathrm{ow}}<2.5\right)$ reveal lower sorption capacities. As shown in Table 1 , the measured $\log \mathrm{K}_{\mathrm{ow}}$ for PEN G and AMX

Table 2 Antibiotics profiling and removal efficiency in four hospitals $(n=72)$

\begin{tabular}{|c|c|c|c|c|c|c|c|}
\hline Hospital & WWTP & Compound & $\begin{array}{l}\text { Influent loading } \\
\text { range }\left(\mathrm{g} \mathrm{day}^{-1}\right)\end{array}$ & Avg & $\mathrm{SD}$ & $\begin{array}{l}\text { Removal efficiency }(\%) \\
\text { after biological processes } \\
\text { (sample 2) }\end{array}$ & $\begin{array}{c}\text { Removal efficiency (\%) } \\
\text { after disinfection } \\
\text { (sample 3) }\end{array}$ \\
\hline \multirow{2}{*}{ A } & \multirow{2}{*}{$\begin{array}{c}\text { Aerobic/ conventional } \\
\text { activated sludge }\end{array}$} & AMX & $0.74-0.1$ & 0.09 & 0.13 & $16.9-33.1$ & $20-37.5$ \\
\hline & & PEN G & $0.25-0.31$ & 0.29 & 0.03 & $22.6-36.1$ & $23-40.6$ \\
\hline \multirow{2}{*}{ B } & \multirow{2}{*}{$\begin{array}{l}\text { Aerobic/ conventional } \\
\text { activated sludge }\end{array}$} & AMX & $0.5-0.9$ & 0.7 & 0.02 & $30.5-38.3$ & $35.5-45$ \\
\hline & & PEN G & $0.02-0.24$ & 0.14 & 0.11 & $36.7-44$ & $40.2-50.3$ \\
\hline \multirow[b]{2}{*}{ C } & \multirow{2}{*}{$\begin{array}{l}\text { Aerobic/ conventional } \\
\text { activated sludge }\end{array}$} & AMX & $0.46-1.02$ & 0.76 & 0.28 & $20.2-35$ & $23.6-48$ \\
\hline & & PEN G & $0.07-0.23$ & 0.16 & 0.076 & $28.6-46$ & $33-50$ \\
\hline \multirow{2}{*}{$\mathrm{D}$} & \multirow{2}{*}{ Anaerobic/ septic tank } & AMX & $0.35-0.52$ & 0.43 & 0.087 & $33.6-52$ & $41-56.6$ \\
\hline & & PEN G & $0.05-0.07$ & 0.06 & 0.011 & $47.1-57.9$ & $53.3-60.5$ \\
\hline
\end{tabular}


are 1.83 and 0.87 , respectively. These values demonstrate that sorption of these antibiotics onto the solids are insignificant, which corroborate with many other pharmaceuticals studied in the literature. ${ }^{35}$ Given the sorption being considered the secondary elimination pathway of antibiotics, biodegradation may be the prominent removal mechanism. Biodegradation of antibiotics under aerobic and anaerobic conditions has been examined in many studies. ${ }^{40-42}$ Moreover, it has been shown to involve two principles; (1) co-metabolism consisting of degradation of the targeted compounds by microbial communities' enzymes or (2) substrate degradation. In the later process, microbial communities exploit the pollutants as being their sources of carbon and energy.$^{43}$ Solubility plays a key role in the biodegradation efficiency of pharmaceuticals. Since the hydrophobic pollutants, having lower solubility, tend to be retained in sewage sludge, there will be more time for microbial degradation. However, hydrophilic compounds, such as most antibiotics, escape from WWTP. ${ }^{44,45}$ On the other hand, the presence of sulphur or halogen elements in the structure of long-chain aliphatic compounds, such as PEN and AMX, has made them more biologically decomposable compared to aromatic substances (Table 1). According to Andreozzi et al. ${ }^{44}$ $\beta$-lactamase enzymes produced by some bacteria are responsible for PEN and AMX deterioration under aerobic circumstances. The study also suggested the successful degradation of PEN through hydrolysis and aerobic processes besides eliminating AMX in batch tests. As mentioned earlier, $\beta$-lactams (PEN and AMX) are among the most commonly used antibiotics; however, they have not been detected in high concentrations in urban wastewater treatment plants. ${ }^{46}$ This could be assigned to the chemical instability of the $\beta$-lactam ring, which alters in various $\mathrm{pH}$, heat and $\beta$-lactamase enzymes. Numerous researches have also revealed high susceptibility of $\beta$-lactam antibiotics to chemical or enzymatic chemical decomposition in WWTP.22,47 Degradation of $\beta$-lactam antibiotics may arise from acidic/alkaline conditions or through reactions with weak nucleophiles like water or metal ions. ${ }^{22,48}$ In such circumstances, some other degrading compounds may be found in water resources. Intermediate compounds, such as penicilloic acid, may become dominant based on the $\mathrm{pH}$ of the medium. ${ }^{49}$ Findings have disclosed some pharmaceutical products of the same community demonstrate significant variations in their removal, i.e. the predominant process for the degradation of tetracycline is sorption. ${ }^{17}$ However, the decline of azithromycin and sulfamethoxazole occurs through degradation. ${ }^{35}$ The halflives of AMX in acidic environments $(\mathrm{pH} 3)$, neutral water ( $\mathrm{pH} 7$ ), and alkaline conditions ( $\mathrm{pH} 11$ ) have been recorded as $128.2,208.3$, and $9.7 \mathrm{~h}$, respectively. ${ }^{48}$ In the current study, PEN G removal was slightly greater than AMX, which might be ascribed to the transformation of human metabolites and conversion of formed AMX metabolites into the parent compounds. However, this difference was not statistically significant $(\mathrm{p}>0.05)$. In a study conducted by Paíga et al. ${ }^{50}$ on pharmaceuticals removal in various WWTPs, antibiotics showed a great oscillation in removal efficiency compared with other groups. Another important parameter that controls biodegradation is SRT. Higher SRT is advantaged by the proliferation and maintenance of slow-growing microorganisms responsible for nitrogen removal at longer SRTs. ${ }^{35}$ Like SRT, longer HRT is favourable if higher pharmaceutical removal is concerned. Gros et al. ${ }^{41}$ reported that HRT is a key parameter in the pharmaceuticals elimination rates, particularly for biodegradable compounds, since with longer HRT, antibiotics spend more time in the bioreactor. The studied WWTP in the present survey are operating at $2-4 \mathrm{~h}$ HRTs and 15 days SRTs. Therefore, with their hydrophobic properties and low HRTs, these antibiotics demonstrated low to medium percentage removal (16.9-46\%).
Furthermore, the septic tank's removal performance, with a 2-3 days retention time, was slightly greater than that of activated sludge processes. This finding could also be explained by the presence of nitrogen and sulphur in the molecular structures of AMX and PEN that might escalate anaerobic degradation. ${ }^{51}$

The results obtained throughout the current study corroborate the findings of many previous works that demonstrate that an exact determination of pharmaceutical removal rate and efficacy is impossible, and only a range can be elucidated. ${ }^{52,53}$ The results of the current study revealed removal variability in the same season (autumn) for each WWTP. Thus, it seems risky to decide on antibiotics removal efficiencies in a specified season just based on the analysis of only two samples. Our research results are in accordance with a study by Thiebault et al. ${ }^{16}$ who pointed out the risk of estimating some pharmaceuticals based on one or two samples.

Overall, inconsistent operational conditions, such as insufficient air supply, unsuitable disinfectant dosage, low SRT and HRT, loss of activated sludge and presence of other pharmaceuticals, might lead to low antibiotics removal efficiency. ${ }^{16}$ Moreover, operators of hospital WWTP are generally not trained in the field of wastewater treatment. The same impediments were reported by Bui et al. ${ }^{19}$ as they highlighted that unspecialised operators are the main cause of insufficient wastewater treatment at the studied health care facilities.

Another factor that should be considered is the chlorine effect on AMX and PEN G degradation. As shown in Table 2, chorine's degree of degradation was not significant since the studied antibiotics' removal efficiency following chlorination in all surveyed hospitals only showed a 5-8\% increment. This small increase could be assigned to insufficient chlorine concentration, low chlorine contact time and the presence of other pharmaceuticals.

\subsection{Wastewater treatment situation and potential influence of wastewater characteristics on removal efficiencies}

Table 3 represents average $\mathrm{COD}, \mathrm{BOD}_{5}$ and TSS concentrations of each hospital's influent and effluent during the monitoring period. The mean removal percentages of TSS, $\mathrm{BOD}_{5}$ and COD were 97.38, 88.34 and 87.37, respectively. As it is clear, these parameters' removal efficacy was high, and WWTPs perform effectively in treating wastewater. However, the effluent quality of three of the studied hospitals operated under aerobic conditions did not meet the national standard limits in terms of $\operatorname{COD}\left(<60 \mathrm{mg} \mathrm{L}^{-1}\right)$ and $\mathrm{BOD}_{5}\left(<30 \mathrm{mg} \mathrm{L}^{-1}\right)$. In contrast, the $\mathrm{COD}$ and $\mathrm{BOD}_{5}$ values of treated wastewater of hospital $\mathrm{D}$ met the discharge criteria. The examined effluent concentrations of TSS in all hospital met the promulgated standards $\left(\right.$ TSS $<30 \mathrm{mgL}^{-1}$ ). The statistical correlation between removal efficiencies of antibiotics and wastewater quality parameters is shown in Table 4 (a), and the corresponding correlation graph is depicted in Table 4(b).

Removal of both antibiotics does not exhibit any statistically significant correlation with TSS. Based on their low $\log \mathrm{K}_{\mathrm{ow}}$ AMX and PEN G's adsorption on TSS is presumably negligible. However, antibiotics removal showed a significant correlation with COD removal and a fairly strong correlation with $\mathrm{BOD}_{5}$ removal, demonstrating the involved processes. Given the secretion of $\beta$-lactamase enzymes, both antibiotics are known to be susceptible to biodegradation. The correlation with the removal of $\mathrm{BOD}_{5}$ indicates that the performance of some processes (particularly those involved in the degradation of carbonaceous organic matter) affects the removal of AMX and PEN G. In line with these results, a study has recently demonstrated statistically significant correlations with Metoprolol removal, $\mathrm{BOD}_{5}$ and $\mathrm{NO}_{2}$ reduction, pointing out that biodegradation and nitrogen removal is the key factors 
Table 3. Influent and effluent characteristics of wastewater at various hospitals (mean \pm S.D; $n=48$ )

\begin{tabular}{|c|c|c|c|c|c|c|}
\hline Hospital & $\begin{array}{c}\mathrm{COD}_{\text {influent }} \pm \mathrm{SD} \\
\left(\mathrm{mgL}^{-1}\right)\end{array}$ & $\begin{array}{c}\text { BOD5i }_{\text {nfluent }} \pm \text { SD } \\
\left(\mathrm{mgL}^{-1}\right)\end{array}$ & $\begin{array}{l}\mathrm{TSS}_{\text {influent }} \pm \mathrm{SD} \\
\left(\mathrm{mgL}^{-1}\right)\end{array}$ & $\begin{array}{c}\mathrm{CODe}_{\text {ffluent }} \pm \mathrm{SD} \\
\left(\mathrm{mgL}^{-1}\right)\end{array}$ & $\begin{array}{c}\mathrm{BOD}_{\text {5effluent }} \pm \mathrm{SD} \\
\left(\mathrm{mgL}^{-1}\right)\end{array}$ & $\begin{array}{c}\mathrm{TSS}_{\text {effluent }} \pm \mathrm{SD} \\
\left(\mathrm{mgL}^{-1}\right)\end{array}$ \\
\hline \multicolumn{7}{|c|}{ October } \\
\hline A & $554 \pm 12$ & $342 \pm 21$ & $620 \pm 35$ & $76 \pm 7$ & $39 \pm 6$ & $24 \pm 11$ \\
\hline B & $662 \pm 6$ & $496 \pm 6$ & $754 \pm 42$ & $84 \pm 9$ & $48 \pm 12$ & $18 \pm 9$ \\
\hline $\mathrm{C}$ & $635 \pm 10$ & $364 \pm 9$ & $982 \pm 33$ & $76 \pm 15$ & $46 \pm 10$ & $19 \pm 5$ \\
\hline $\mathrm{D}$ & $342 \pm 15$ & $298 \pm 17$ & $542 \pm 15$ & $36 \pm 11$ & $29 \pm 3$ & $30 \pm 3$ \\
\hline \multicolumn{7}{|c|}{ November } \\
\hline A & $520 \pm 12$ & $354 \pm 13$ & $789 \pm 12$ & $86 \pm 5$ & $49 \pm 12$ & $8 \pm 1$ \\
\hline B & $652 \pm 21$ & $582 \pm 23$ & $527 \pm 21$ & $84 \pm 10$ & $65 \pm 9$ & $13 \pm 3$ \\
\hline C & $635 \pm 30$ & $398 \pm 30$ & $982 \pm 23$ & $76 \pm 14$ & $57 \pm 10$ & $19 \pm 6$ \\
\hline $\mathrm{D}$ & $378 \pm 15$ & $298 \pm 10$ & $852 \pm 10$ & $37 \pm 3$ & $21 \pm 11$ & $6 \pm 1$ \\
\hline \multicolumn{7}{|c|}{ December } \\
\hline A & $650 \pm 12$ & $411 \pm 10$ & $625 \pm 12$ & $60 \pm 10$ & $60 \pm 6$ & $15 \pm 5$ \\
\hline B & $552 \pm 15$ & $451 \pm 12$ & $498 \pm 15$ & $46 \pm 6$ & $46 \pm 7$ & $17 \pm 9$ \\
\hline C & $635 \pm 6$ & $364 \pm 17$ & $852 \pm 23$ & $46 \pm 6$ & $46 \pm 4$ & $22 \pm 3$ \\
\hline $\mathrm{D}$ & $485 \pm 10$ & $284 \pm 11$ & $611 \pm 30$ & $36 \pm 5$ & $36 \pm 10$ & $19 \pm 4$ \\
\hline
\end{tabular}

Table 4. (a) Correlation between removal efficiency of antibiotics and some wastewater quality parameters and (b) its correlation matrix $(n=48)$ (a)

\begin{tabular}{lccccc} 
Antibiotics & COD & BOD $_{5}$ & TSS & Amoxicillin & Penicillin G \\
\hline Amoxicillin & $0.58^{*}$ & 0.34 & -0.08 & 1 & $0.67^{*}$ \\
& & & & & \\
Penicillin G & $0.76^{*}$ & 0.35 & 0.01 & $0.67^{*}$ & 1
\end{tabular}

(b)

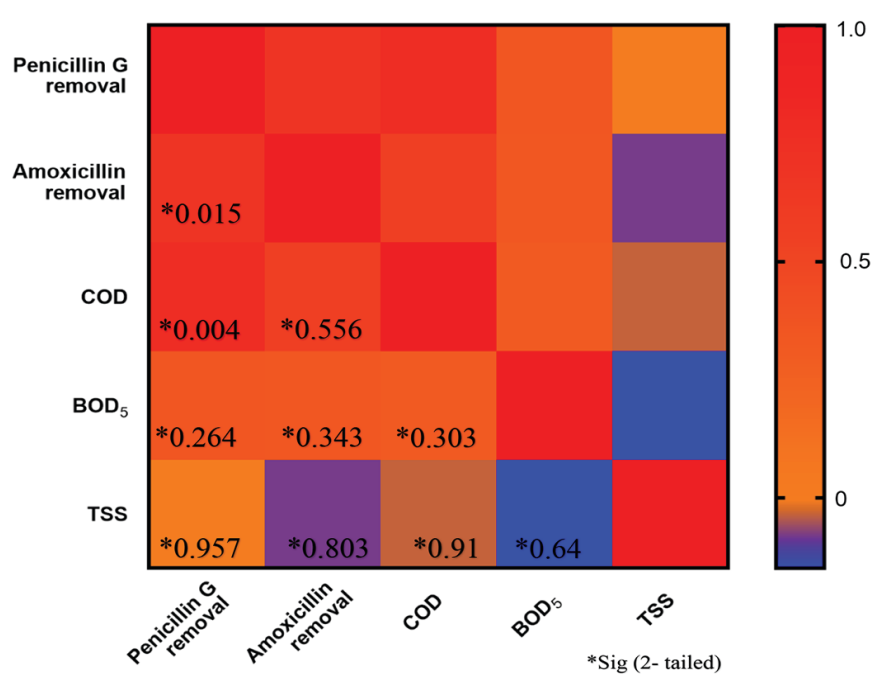

concerning its removal. ${ }^{15}$ Likewise, Sari et al. ${ }^{54}$ observed a strong correlation between the diclofenac removal rate and the nitrogen removal efficiency in WWTP. Santos et al..$^{55}$ exhibited varying (positive or negative) associations between removal of pharmaceutical compounds and wastewater physiochemical parameters.

A weak but significant correlation was observed between AMX and PEN G removal $(r=0.67)$. Similar correlations have been reported between several antibiotics; including PEN and AMX in influents and effluents of HWWTP in Qatar. ${ }^{56}$ As both PEN and AMX appertain to the same antibiotics class (i.e., $\beta$-lactam), their interaction is thus supposed.

\section{Conclusions}

This survey represents the detection and quantification of two widely used antibiotics, AMX and PEN G, in the raw wastewater entering HWWTPs in autumn and their fate and effect in waste treatment units. The target antibiotics were all detected in the influent and effluent samples. Concentrations of measured AMX and PEN G in the four hospital's wastewater influents ranged from 9.8 to $21.95 \mu \mathrm{gL}^{-1}$ and from 0.6 to 6.6 $\mu \mathrm{gL}^{-1}$, respectively. Although both antibiotics' concentrations in the effluents were lower than their raw wastewater values, their removals were incomplete. Maximum removal efficiencies (48\% and $50.3 \%$, respectively) of AMX and PEN G in aerobic WWTP by conventional physical, biological treatment and disinfection processes were obtained. In contrast, the septic tank (anaerobic process) revealed higher removal efficiencies of both antibiotics with respective values of 56.6 and $60.5 \%$. The removal efficiency of antibiotics showed a strong dependence on $\mathrm{COD}$ and, to some extent, with $\mathrm{BOD}_{5}$ while their removal was not correlated significantly with TSS reduction.

In conclusion, high concentrations of PEN, AMX and their intermediate residues discharged into streams can pose a great threat to aquatic ecosystems and diversely affect human health. There is abundant room for further progress in determining additional pharmaceuticals and other emerging contaminants in the hospital wastewater of Iran and their metabolites and biodegradation products.

\section{Acknowledgement}

This research was part of a master's thesis conducted in Tehran Medical Sciences, Islamic Azad University, Tehran, Iran.

\section{ORCID iDs}

Maryam Golchin: https://orcid.org/0000-0002-8881-6690

Mohammadreza Khani: https://orcid.org/0000-0002-8853-0158

Mohsen Sadani: https://orcid.org/0000-0002-2321-0866

Mehdi Sadeghi: https://orcid.org/0000-0001-9095-5449

Mahsa Jahangiri-rad: https://orcid.org/0000-0002-1626-4014

\section{References}

1. S, Jobling, R. Williams, A. Johnson, A. Taylor, M. Gross-Sorokin, M. Nolan, et al. Predicted exposures to steroid estrogens in UK rivers correlate with widespread sexual disruption in wild fish populations. Environ. Health Perspect., 2005, 114(Suppl 1): 32-39.

2. A. Watkinson, E. Murby, D. W. Kolpin, S. Costanzo, The occurrence of antibiotics in an urban watershed: from wastewater to drinking water, Sci. Total Environ., 2009, 407, 2711-2723. 
3. A. Grossberger, Y. Hadar, T. Borch, B. Chefetz, Biodegradability of pharmaceutical compounds in agricultural soils irrigated with treated wastewater, Environ. Pollut. , 2014, 185, 168-177.

4. S.R. Hughes, P. Kay, L.E. Brown, Global synthesis and critical evaluation of pharmaceutical data sets collected from river systems, Environ. Sci. Technol. , 2012, 47, 661-677.

5. W. Xu, G. Zhang, X. Li, S. Zou, P. Li, Z. Hu, J. Li, Occurrence and elimination of antibiotics at four sewage treatment plants in the Pearl River Delta (PRD), South China, Water Res., 2007, 41, 4526-4534

6. B.I. Escher, R. Baumgartner, M. Koller, K. Treyer, J. Lienert, C.S. McArdell, Environmental toxicology and risk assessment of pharmaceuticals from hospital wastewater, Water Res., 2011, 45, 75-92.

7. L. Gunnarsson, A. Jauhiainen, E. Kristiansson, O. Nerman, D. J. Larsson, Evolutionary conservation of human drug targets in organisms used for environmental risk assessments, Environ. Sci. Technol., 2008, 42, 5807-5813.

8. World Health Organization. WHO's first global report on antibiotic resistance reveals serious, worldwide threat to public health 2014. At http://www.who.int/mediacentre/news/releases/2014/amr-report/en/

9. A. Rahbarimanesh, S.Y. Mojtahedi, P. Sadeghi, M. Ghodsi, S. Kianfar, L. Khedmat, S.J.M. Siyahkali, M.K. Yazdi, A. Izadi, Antimicrobial stewardship program (ASP): an effective implementing technique for the therapy efficiency of meropenem and vancomycin antibiotics in Iranian pediatric patients, Ann. Clin. Microbiol. Antimicrob., 2019, 18, 6

10. A. Fahimzad, Z. Eydian, A. Karimi, F. Shiva, S. Armin, R.M. Ghanaei, F. Fallah, S. R. Tabatabaei, F. Shirvani, M. Rahbar, Antibiotic prescribing pattern in neonates of seventeen Iranian hospitals, Arch. Pediatr. Infect. Dis., 2017, 5(4) e61630

11. R. Shokoohi, M. Leili, A. Dargahi, Y. Vaziri, R. Khamutian, Common Antibiotics in Wastewater of Sina and Besat Hospitals, Hamadan, Iran, Arch, Hygiene Sci., 2017, 6, 152-159

12. E. Salehifar, M. Nasehi, G. Eslami, S. Sahraei, R.A. Navaei, Determination of antibiotics consumption in buali-sina pediatric hospital, sari 2010-2011, Iran. J Pharm. Res.: IJPR, 2014, 13, 995-1002.

13. Y. Zhang, S.-U. Geißen, C. Gal, Carbamazepine and diclofenac: removal in wastewater treatment plants and occurrence in water bodies, Chemosphere, 2008, 73, 1151-1161.

14. Antibiotic Chart simple. 2004. http://www.lymepa.org/Antibiotics_ spreadsheet_2004-1215.pdf.

15. M. Patel, R. Kumar, K. Kishor, T. Mlsna, C. U. Pittman, D. Mohan, Pharmaceuticals of emerging concern in aquatic system: chemistry, Occurrence, effects, and removal methods, Chem. Rev., 2019, 119, 3510-3673.

16. T. Thiebault, M. Boussafir, C. Le Milbeau, Occurrence and removal efficiency of pharmaceuticals in an urban wastewater treatment plant: mass balance, fate and consumption assessment, J. Environ. Chem. Eng., 2017, 5, 2894-2902.

17. M. Kim, P. Guerra, A. Shah, M. Parsa, M. Alaee, S. Smyth, Removal of pharmaceuticals and personal care products in a membrane bioreactor wastewater treatment plant, Water Sci. Technol., 2014, 69, 2221-2229.

18. A. Dordio, A.P. Carvalho, D.M. Teixeira, C.B. Dias, A.P. Pinto, Removal of pharmaceuticals in microcosm constructed wetlands using Typha spp. and LECA, Bioresour. Technol., 2010, 101, 886-892.

19. X.-T. Bui, V.-P. Luu, T.-T. Nguyen, B.-T. Dang, M.-Q. Thai, D.-D. Nguyen, T.-S. Nguyen, Q.-T. Dinh, T.-S. Dao, Investigation of antibiotics in health care wastewater in Ho Chi Minh City, Vietnam, Environ. Monit. Assess. , 2016, 188, 686-700.

20. APHA, Standard Methods for Examination of Water and Wastewater, 20th ed, 1998.

21. K. Kümmerer, Antibiotics in the aquatic environment-a review-part I, Chemosphere, 2009, 75, 417-434.

22. N. Le-Minh, S. Khan, J. Drewes, R. Stuetz, Fate of antibiotics during municipal water recycling treatment processes, Water Res., 2010, 44, 4295-4323.

23. Lindberg R. Environmental chemistry, department of chemistry, Umea University, Umea, Sweden. Determination of antibiotics in the Swedish environment with emphasis on Sewage Treatment Plants. 2006.
24. C. Kihampa, $\beta$-lactams and Fluoroquinolone Antibiotics in influents and effluents of Wastewater treatment plants, Dar es Salaam, Tanzania, Research J. Chem. Sci.,2014, 2231, 606-611.

25. J. Radjenović, M. Petrović, D. Barceló, Fate and distribution of pharmaceuticals in wastewater and sewage sludge of the conventional activated sludge (CAS) and advanced membrane bioreactor (MBR) treatment, Water Res., 2009, 43, 831-841.

26. S. J. Kimosop, Z. Getenga, F. Orata, V. Okello, J. Cheruiyot, Residue levels and discharge loads of antibiotics in wastewater treatment plants (WWTPs), hospital lagoons, and rivers within Lake Victoria Basin, Kenya, Environ. Monit. Assess., 2016, 188, 532-537.

27. R. Varela, S. André, O.C. Nunes, C.M. Manaia, Insights into the relationship between antimicrobial residues and bacterial populations in a hospital-urban wastewater treatment plant system, Water Res., 2014, 54, 327-336.

28. I.M. Al-Riyami, M. Ahmed, A. Al-Busaidi, B. Choudri, Antibiotics in wastewaters: a review with focus on Oman, Appl. Water Sci., 2018, 8, 199-211.

29. J. Heidler, R.U. Halden, Meta-analysis of mass balances examining chemical fate during wastewater treatment, Environ. Sci. Technol., 2008, 42, 6324-6332.

30. A. Hartmann, A.C. Alder, T. Koller, R.M. Widmer, Identification of fluoroquinolone antibiotics as the main source of umuC genotoxicity in native hospital wastewater, Environ. Sci. Technol., 1998, 17, 377-382.

31. K.D. Brown, J. Kulis, B. Thomson, T.H. Chapman, D.B. Mawhinney, Occurrence of antibiotics in hospital, residential, and dairy effluent, municipal wastewater, and the Rio Grande in New Mexico, Sci. Total Environ. , 2006, 366, 772-783

32. F. Jafari, A. Khatony, E. Rahmani, Prevalence of self-medication among the elderly in Kermanshah-Iran, Glob. J. Health Sci., 2015, 7, 360.

33. D. Li, M. Yang, J. Hu, Y. Zhang, H. Chang, F. Jin, Determination of penicillin $\mathrm{G}$ and its degradation products in a penicillin production wastewater treatment plant and the receiving river, Water Res., 2008, 42, 307-317.

34. M. Bonyadian, H. Moshtaghi, M.A. Taheri, in Veterinary research forum: an international quarterly journal, Vol. 5, Faculty of Veterinary Medicine, Urmia University, Urmia, Iran, 2014, p. 29.

35. M. Carballa, F. Omil, J. M. Lema, M. a. Llompart, C. García-Jares, I. Rodríguez, M. Gomez, T. Ternes, Behavior of pharmaceuticals, cosmetics and hormones in a sewage treatment plant, Water Res., 2004, 38, 2918-2926.

36. S. Suárez, M. Carballa, F. Omil, J.M. Lema, How are pharmaceutical and personal care products (PPCPs) removed from urban wastewaters?, Rev. Environ. Sci. Biotechnol. , 2008, 7, 125-138.

37. H.R. Rogers, Sources, behaviour and fate of organic contaminants during sewage treatment and in sewage sludges, Sci. Total Environ., 1996, 185, 3-26.

38. M. Rand-Weaver, L. Margiotta-Casaluci, A. Patel, G.H. Panter, S.F. Owen, J.P. Sumpter, The read-across hypothesis and environmental risk assessment of pharmaceuticals, Environ. Sci. Technol., 2013, 47, 11384-11395.

39. J. Sipma, B. Osuna, N. Collado, H. Monclús, G. Ferrero, J. Comas, I. Rodriguez-Roda, Comparison of removal of pharmaceuticals in MBR and activated sludge systems, Desalination, 2010, 250, 653-659.

40. B. Blair, A. Nikolaus, C. Hedman, R. Klaper, T. Grundl, Evaluating the degradation, sorption, and negative mass balances of pharmaceuticals and personal care products during wastewater treatment, Chemosphere, 2015, 134, 395-401.

41. M. Gross, M. Petrović, A. Ginebreda, D. Barceló, Removal of pharmaceuticals during wastewater treatment and environmental risk assessment using hazard indexes. Environ. Int., 2010, 36 (1), 15-26.

42. L. Feng, M.E. Casas, L.D.M. Ottosen, H.B. Møller, K. Bester, Removal of antibiotics during the anaerobic digestion of pig manure, Sci. Total Environ., 2017, 603, 219-225.

43. A. Jelic, M. Gros, A. Ginebreda, R. Cespedes-Sánchez, F. Ventura, M. Petrovic, D. Barcelo, Occurrence, partition and removal of pharmaceuticals in sewage water and sludge during wastewater treatment, Water Res., 2011, 45, 1165-1176. 
44. A. Joss, H. Andersen, T. Ternes, P.R. Richle, H. Siegrist, Removal of estrogens in municipal wastewater treatment under aerobic and anaerobic conditions: consequences for plant optimization, Environ. Sci. Technol., 2004, 38, 3047-3055.

45. R. Andreozzi, V. Caprio, C. Ciniglia, M. De Champdoré, R. Lo Giudice, R. Marotta, E. Zuccato, Antibiotics in the environment: occurrence in Italian STPs, fate, and preliminary assessment on algal toxicity of amoxicillin, Environ. Sci. Technol., 2004, 38, 6832-6838.

46. T. Zhang, B. Li, Occurrence, transformation, and fate of antibiotics in municipal wastewater treatment plants, Crit. Rev. Environ. Sci. Technol., 2011, 41, 951-998.

47. A. Watkinson, E. Murby, S. Costanzo, Removal of antibiotics in conventional and advanced wastewater treatment: implications for environmental discharge and wastewater recycling, Water Res., 2007, 41, 4164-4176.

48. K. Hirte, B. Seiwert, G. Schüürmann, T. Reemtsma, New hydrolysis products of the beta-lactam antibiotic amoxicillin, their $\mathrm{pH}$ dependent formation and search in municipal wastewater, Water Res., 2016, 88, 880-888.

49. I. Gozlan, A. Rotstein, D. Avisar, Amoxicillin-degradation products formed under controlled environmental conditions: identification and determination in the aquatic environment, Chemosphere, 2013, 91, 985-992.

50. P. Paíga, L. H. Santos, S. Ramos, S. Jorge, J. G. Silva, C. Delerue-Matos, Presence of pharmaceuticals in the Lis river (Portugal): Sources, fate and seasonal variation, Sci. Total Environ., 2016, 573, 164-177.
51. M. Carballa, G. Fink, F. Omil, J. M. Lema, T. Ternes, Determination of the solid-water distribution coefficient (Kd) for pharmaceuticals, estrogens and musk fragrances in digested sludge, Water Res., 2008, 42, 287-295.

52. K.C. Wijekoon, J.A. McDonald, S.J. Khan, F.I. Hai, W.E. Price, L.D. Nghiem, Development of a predictive framework to assess the removal of trace organic chemicals by anaerobic membrane bioreactor, Bioresour. Technol., 2015, 189, 391-398.

53. B. Petrie, R. Barden, B. Kasprzyk-Hordern, A review on emerging contaminants in wastewaters and the environment: current knowledge, understudied areas and recommendations for future monitoring, Water Res., 2015, 72, 3-27.

54.S. Sari, G. Ozdemir, C. Yangin-Gomec, G.E. Zengin, E. Topuz, E. Aydin, E. Pehlivanoglu-Mantas, D.O. Tas, Seasonal variation of diclofenac concentration and its relation with wastewater characteristics at two municipal wastewater treatment plants in Turkey, J. Hazard. Mater., 2014, 272, 155-164.

55. J. Santos, I. Aparicio, M. Callejón, E. Alonso, Occurrence of pharmaceutically active compounds during 1-year period in wastewaters from four wastewater treatment plants in Seville (Spain), J. Hazard. Mater., 2009, 164, 1509-1516.

56. S. Al-Maadheed, I. Goktepe, A.B.A. Latiff, B. Shomar, Antibiotics in hospital effluent and domestic wastewater treatment plants in Doha, Qatar, J. Water Process Eng., 2019, 28, 60-68. 